\title{
APLIKASI UNTUK MENENTUKAN IP ADDRESS DAN SUBNETMASK HOST PADA SUATU JARINGAN
}

\author{
Ahmad Mubarak, Fathul Wahid \\ Jurusan Teknik Informatika, Fakultas Teknologi Industri, Universitas Islam Indonesia \\ Jl. Kaliurang Km. 14 Yogyakarta 55501 \\ Telp. (0274) 895287 ext. 122, Faks. (0274) 895287 ext. 147 \\ E-mail: thommey2000@yahoo.com; fathulwahid@fti.uii.ac.id
}

\begin{abstract}
ABSTRAK
Salah satu protokol pendukung komunikasi jaringan adalah TCP/IP, protokol ini diberikan pada setiap komputer yang terhubung pada suatu jaringan agar bisa dikenali dalam jaringan tersebut. Dalah hal ini setiap komputer diberikan alamat logika (IP address). Penelitian ini membahas aplikasi untuk menentukan alamat IP dan subnetmask host pada jaringan perusahaan dengan metode subnetting. Tujuan penelitian adalah untuk membangun software aplikasi yang memberikan kemudahan pada user dalam menentukan IP address dan menentukan subnetmask host pada masing-masing departemen yang terdapat dalam suatu jaringan secara bijaksana berdasarkan jumlah PC masing-masing departemen. Hasil akhir dari keluaran sistem berupa nomor network baru, rentang alamat $I P$, alamat broadcast, dan subnetmask untuk masing-masing departemen.
\end{abstract}

Kata kunci: IP address, subnetmask, host, broadcast.

\section{PENDAHULUAN}

IP address merupakan alamat logika yang di berikan ke semua perangkat jaringan yang menggunakan protokol TCP/IP. IP address memungkinkan host pada jaringan yang berbeda maupun pada jaringan yang sama untuk bisa saling berkomunikasi walaupun dlm platform yang berbeda. Untuk mengatasi kesulitan dalam perhitungan alamat IP munculah suatu metode yang dinamakan subnetting yang berfungsi memperbanyak Network ID dimiliki dengan cara mengorbankan sebagian Host ID untuk membuat Network ID tambahan.

Berdasarkan hal tersebut maka akan dibangun sebuah software aplikasi yang dapat membantu seorang user dalam menentukan IP Address host yang ada pada suatu jaringan secara efektif dengan pertimbangan banyaknya jumlah host yang ada pada masing-masing divisi/departemen.

Penelitian ini memiliki batasan sebagai berikut:

a. Aplikasi akan menampilkan hasil dari prosses subnetting yang dari masingmasing divisi/departemen.

b. Rentang IP Address pada setiap divisi/departemen bisa berbeda-beda berdasarkan jumlah host yang telah user inputkan sebelumnya.

c. Jumlah divisi/departemen dibatasi maksimal 10.

d. IP yang digunakan adalah IPv4 (IP version 4). 
e. Kelas IP yang digunakan adalah kelas A, B dan C

f. Aplikasi ini dijalankan dalam sistem operasi Microsoft Windows.

\section{LANDASAN TEORI}

\subsection{IP Address}

IP address merupakan bilangan biner 32 bit yang terbagi menjadi empat kelompok, sehingga masing-masing kelompok terdiri dari bilangan biner 8 bit. Ini merupakan implementasi alamat IP yang disebut IPv4 (Wagito, 2005). Sebagai contoh:

11000000.10101000 .01100100 .01100111

alamat IP di atas setelah di konversi ke desimal menjadi: 192.168.100.103

Masing-masing kelompok bit biner terdiri dari 8 bit, sehingga jika diubah menjadi bilangan desimal, maka bilangan yang mungkin adalah dari 0 (biner $=$ 00000000) sampai 255 (biner $=11111111$ ) yaitu ada 256 bilangan desimal.

\subsection{Jenis IP Address}

a. Classfull

Classfull merupakan metode pembagian IP address berdasarkan kelas dimana IP address (yang berjumlah sekitar 4 milyar) dibagi ke dalam lima kelas, yaitu kelas A, B, C, D dan E.

b. Classless

Classless addressing disebut juga sebagai pengalamatan tanpa kelas. Classless addressing Saat ini mulai banyak diterapkan, yakni dengan mengalokasikan IP address dalam notasi Classless Inter Domain Routing (CIDR). Istilah lain yang digunakan untuk menyebut bagian IP address yang menunjuk suatu jaringan secara lebih spesifik disebut juga dengan Network Prefik. Biasanya dalam menuliskan network prefix suatu kelas IP address digunakan tanda garis miring (slash) "/" diikuti dengan angka yang menunjukkan panjang network prefix dalam bit.

\subsection{Network ID, Host ID, dan Broadcast}

Alamat IP pada dasarnya terbagi menjadi dua bagian yaitu Network ID dan Host ID. Network ID untuk menentukan alamat jaringan, sedangkan Host ID menentukan alamat host. Secara simbolik IP address juga bisa dituliskan sebagai 4 kelompok huruf seperti pada tabel 1. Selain itu IP address juga dapat dituliskan seperti yang tampak dalam tabel 2.

Tabel 1. Tabel simbolisasi IP address

\begin{tabular}{|l|l|l|l|}
\hline $\mathrm{W}$ & $\mathrm{X}$ & $\mathrm{Y}$ & $\mathrm{Z}$ \\
\hline
\end{tabular}


Tabel 2. Tabel Network ID dan Host ID

\begin{tabular}{|l|l|l|l|}
\hline Kelas & Network ID & Host ID & Default Subnet Mask \\
\hline A & w. & x.y.z & 255.0 .0 .0 \\
\hline B & w.x & y.z & 255.255 .0 .0 \\
\hline C & w.x.y & z & 255.255 .255 .0 \\
\hline
\end{tabular}

Network ID akan menentukan alamat jaringan peralatan tersebut. Alamat jaringan adalah alamat IP yang mana bit bilangan bagian host semuanya dibuat menjadi 0. Alamat jaringan akan menentukan lokasi peralatan dalam sistem jaringan, apakah ada pada lokasi yang sama atau tidak.

Host ID menentukan nomor host atau kartu jaringan untuk peralatan jaringan yang dimaksud. Bagian host akan menentukan alamat host.

Selain alamat jaringan dan alamat host, juga dapat diambil pengertian tentang alamat broadcast. Alamat broadcast adalah IP address yang semua bit bilangan bagian host dibuat menjadi 1. Alamat broadcast digunakan untuk berbicara secara simultan kepada semua peralatan dalam satu jaringan.

\section{METODE PERANCANGAN}

Metode perancangan perangkat lunak yang digunakan untuk mengelementasikan adalah dengan metode berarah aliran data. Metode ini menyajikan diagram alir (flowchart) yang menggambarkan proses pemasukan data pada sistem, bagaimana data diproses sampai dengan penyajian data kepada user. Pada perancangan ini digunakan perancangan arsitektural.

Perancangan arsitektural merupakan pembuatan sistem aplikasi dari Perhitungan IP Address beserta implementasinya dengan menggunakan pemrograman yang sesuai dengan karakteristik software tersebut, bagian umum dari aplikasi ini bisa dilihat pada gambar 1 untuk pilihan manual dan gambar 2 untuk pilihan otomatis.



Gambar 1. Struktur Umum Software aplikasi Perhitungan IP Address Manual

Penjelasan dari bagian-bagian struktur umum sofware aplikasi Perhitungan IP address manual adalah sebagai berikut: 
1. Input

Bagian Input adalah bagian dalam memberikan data yang dibutuhkan agar dapat diproses melalui software aplikasi Perhitungan IP Address. Pada bagian ini user menginputkan data Nomer Network yang akan di subnettkan, jumlah departemen dan nama departemen beserta jumlah PC masing-masing departemen.

2. Proses

Bagian Proses adalah bagian untuk mengeksekusi semua fungsi maupun prosedur dari keseluruhan proses pada software aplikasi Perhitungan IP Address ini. Pada Bagian ini sistem akan memproses data yang telah di inputkan user. Pertama-tama sistem akan membaca nomer network, Jumlah departemen dan Jumlah PC masing-masing departemen yang telah di inputkan user. Berikutnya sistem akan menentukan Kelas IP berdasarkan nomer network yang telah di inputkan. Kemudian sistem akan membaca jumlah PC tertinggi dari data yang telah diinputkan user, apakah masuk dalam rentang jumlah maksimum host pada kelas tersebut atau tidak. Jika Ya maka sistem akan melakukan proses subnetting, namun jika tidak, sistem akan menentukan kelas mana yang tepat untuk jumlah PC tersebut, kemudian melakukan proses subnetting setelah menentukan nomer network baru.

3. Output

Bagian Output adalah bagian akhir dari keseluruhan proses pada software aplikasi Perhitungan IP Address. Pada software ini data hasil akhir dari proses adalah berupa data hasil subnetting diantaranya adalah: Nomer Network masing-masing departemen, Rentang IP Address berdasarkan jumlah PC masing-masing departemen, Alamat Broadcast dan Subnetmask.

Untuk proses kerja sistem bisa dilihat dari pseude code berikut:

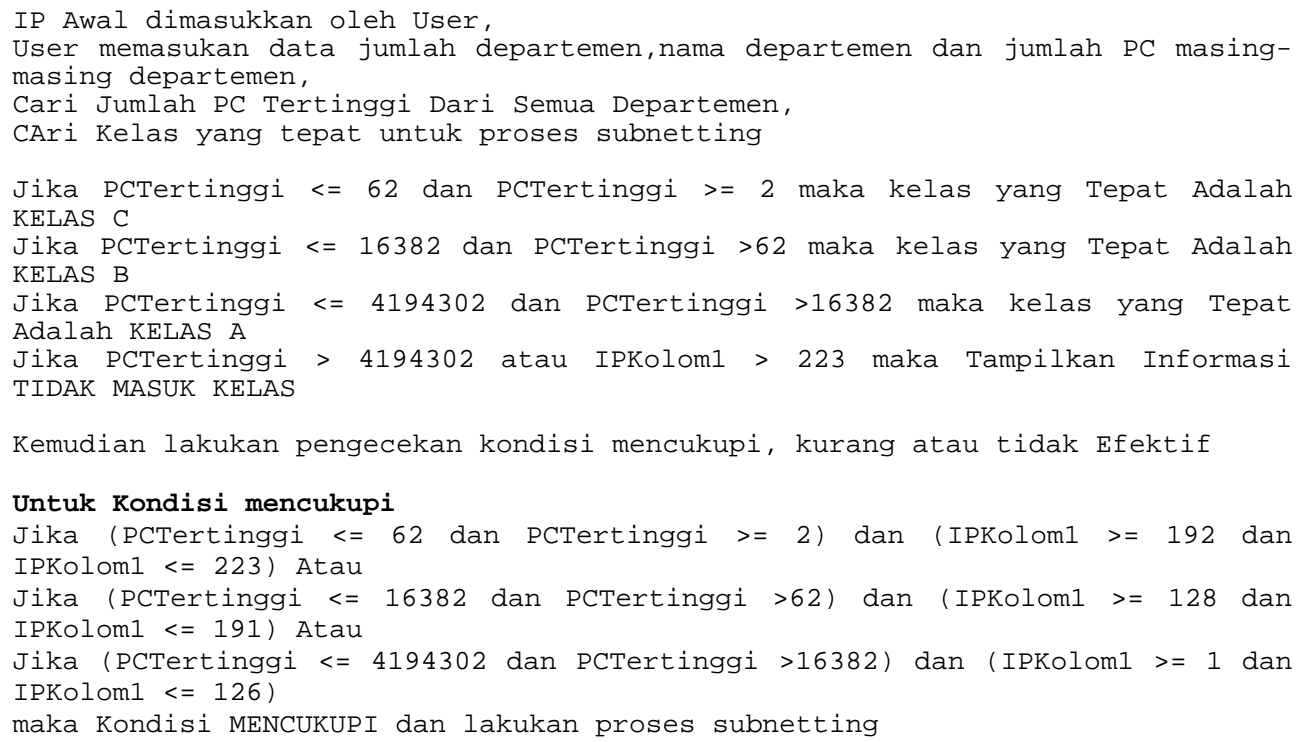




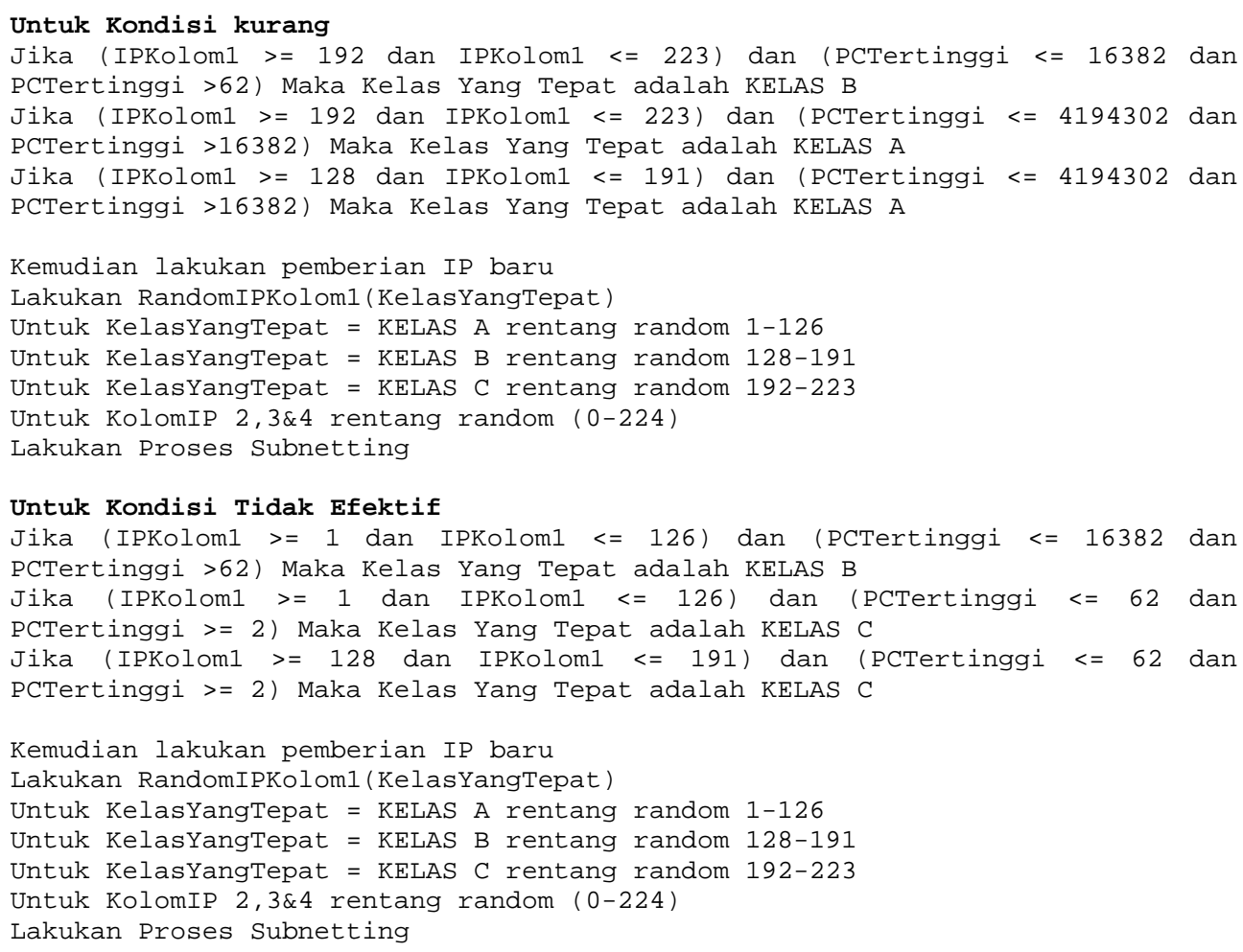

Sedangkan perancangan arsitektural sistem untuk pilihan otomatis digambarkan sebagai bagan alir yang tampak pada gambar 2 .

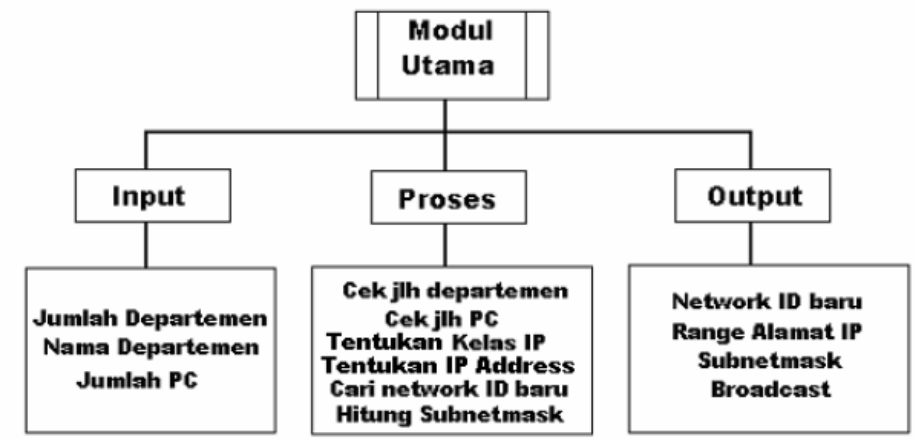

Gambar 2. Struktur Umum Software aplikasi Perhitungan IP Address Otomatis

Penjelasan dari bagian-bagian struktur umum sofware aplikasi Perhitungan IP Address otomatis adalah sebagai berikut:

1. Input

Bagian Input adalah bagian dalam memberikan data yang dibutuhkan agar dapat diproses melalui software aplikasi Perhitungan IP Address. Berbeda dengan subneeting manual, pada bagian ini user tidak menginputkan nomer 
network tetapi hanya menginputkan data Jumlah departemen dan nama departemen beserta jumlah PC masing-masing departemen.

2. Proses

Bagian Proses adalah bagian untuk mengeksekusi semua fungsi maupun prosedur dari keseluruhan proses pada software aplikasi Perhitungan IP Address ini. Pada Bagian ini sistem akan memproses data yang telah di inputkan user. Pertama-tama sistem akan membaca jumlah PC tertinggi dari data yang telah diinputkan user. Berikutnya sistem akan menentukan kelas mana yang lebih efisien untuk jumlah PC tersebut. Kemudian sistem akan memberikan alamat IP secara acak sesuai dengan kelas yang telah ditentukan untuk melakukan proses subnetting.

3. Output

Bagian Output adalah bagian akhir dari keseluruhan proses pada software aplikasi Perhitungan IP Address. Pada software ini data hasil akhir dari proses adalah berupa data hasil subnetting diantaranya adalah: Nomor Network masing-masing departemen, Rentang IP Address berdasarkan jumlah PC masing-masing departemen, Alamat Broadcast dan Subnetmask.

Untuk proses kerja sistem dapat dilihat dari pseude code berikut:

User memasukan data jumlah departemen, nama departemen dan jumlah PC masing-masing departemen,

Cari Jumlah PC Tertinggi Dari Semua Departemen

CAri Kelas yang tepat untuk proses subnetting

Jika PCTertinggi <= 62 dan PCTertinggi s= 2 maka kelas yang Tepat Adalah KELAS C

Jika PCTertinggi <= 16382 dan PCTertinggi >62 maka kelas yang Tepat Adalah KELAS B

Jika PCTertinggi <= 4194302 dan PCTertinggi >16382 maka kelas yang Tepat Adalah KELAS A

Jika PCTertinggi > 4194302 atau IPKolom1 > 223 maka Tampilkan Informasi

TIDAK MASUK KELAS

Kemudian Tentukan IP address yang akan disubnettkan dengan cara :

Lakukan RandomIPKolom1(KelasYangTepat)

Untuk KelasYangTepat = KELAS A rentang random 1-126

Untuk KelasYangTepat $=$ KELAS B rentang random 128-191

Untuk KelasYangTepat $=$ KELAS C rentang random 192-223

Untuk KolomIP 2,3\&4 rentang random (0-224)

Lakukan Proses Subnetting

Untuk proses subnetting dapat dilihat dalam pseude code berikut:

Tentukan (Pangkat Terdekat - 2) yang hasilnya >= Jumlah host departemen

Tentukan Bit Host Baru

Untuk Kelas A mempunyai 24 bit host standard

Bit Host BAru Kelas A = Pangkat Terdekat

Untuk Kelas B mempunyai 16 bit host standard

Bit Host BAru Kelas $\mathrm{B}=$ Pangkat Terdekat

Kelas C mempunyai 8 bit host standard

Bit Host BAru Kelas $\mathrm{C}=$ Pangkat Terdekat 
Tentukan Bit Network

Kelas A mempunyai 24 bit host standard

Bit Network Kelas A : BitHostStandardKelasA - Pangkat Terdekat

Tentukan Subnetmask Baru

Kelas B mempunyai 16 bit host standard

Bit Network Kelas B : BitHostStandardKelasB - Pangkat Terdekat

Tentukan Subnetmask Baru

Kelas $C$ mempunyai 8 bit host standard

Bit Network Kelas C : BitHostStandardKelasC - Pangkat Terdekat

Tentukan Subnetmask Baru

Tentukan Jumlah Subnet yang mungkin

Jumsubnet Yang mungkin : $2^{\wedge}$ BitNetwork(KelasYgTepat)

Tentukan Kelipatan Kelompok Tabel IP

256 - Subnetmask Baru

\section{IMPLEMENTASI}

Halaman utama merupakan tampilan yang memuat berbagai macam kebutuhan sistem, diantaranya adalah kebutuhan input, output dan menu, seperti yang terlihat pada gambar 3 .

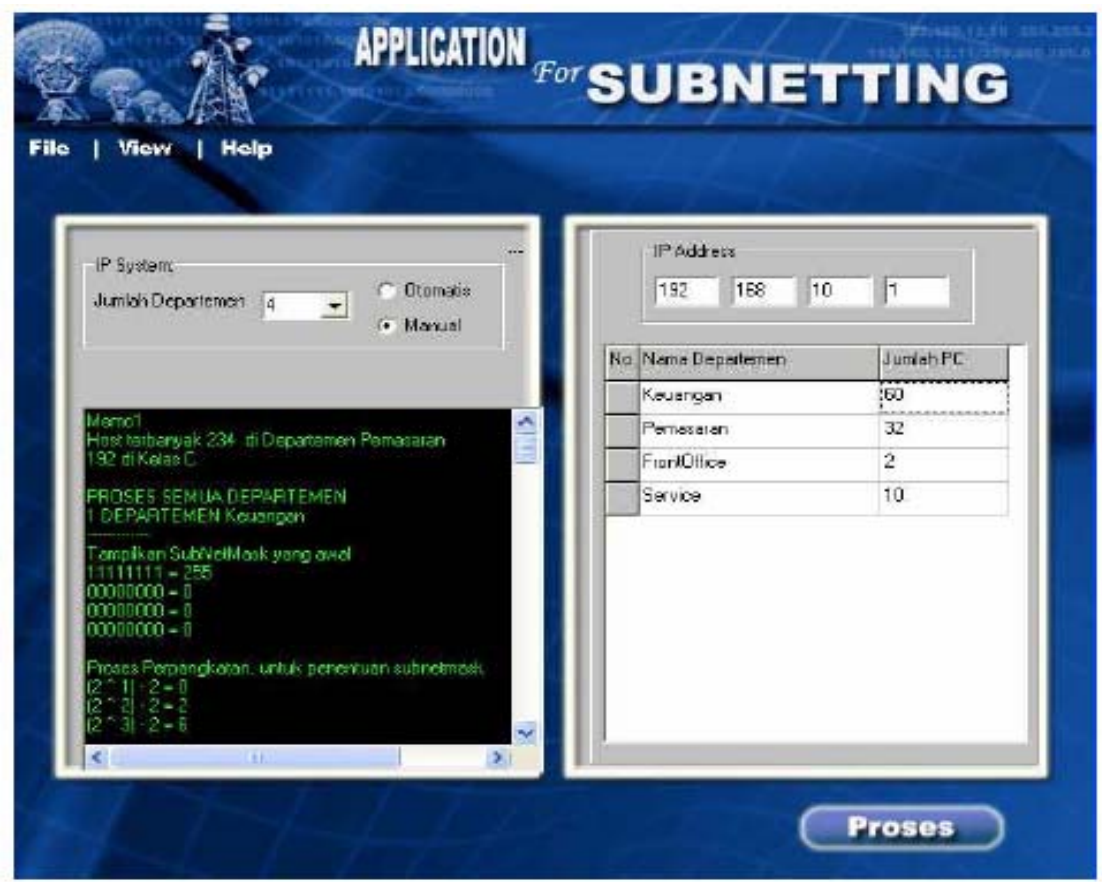

Gambar 3. HalamanUtama

Di dalam tampilan utama terdapat 2 aktifitas bagi user untuk berinteraksi dengan sistem yaitu:

1. Pilihan Manual

Urutan langkah proses Manual adalah sebagai berikut: 
a. Klik ComboBox jumlah departemen pilih jumlah yang dibutuhkan

b. Klik opsi RadioButton Manual

c. Inputkan IP Address yang akan di subnetkan

d. Inputkan Nama Departemen pada StringGrid yang tersedia

e. Inputkan Jumlah PC masing-masing departemen yang terdapat pada tringGrid.

2. Pilihan Otomatis

Urutan langkah pilihan otomatis tidak jauh beda dengan proses manual, hanya saja pada pilihan otomatis user tidak diharuskan menginputkan IP Address. Langkah prosesnya adalah sebagai berikut:

a. Klik ComboBox jumlah departemen pilih jumlah yang dibutuhkan

b. Klik opsi RadioButton Otomatis

c. Inputkan Nama Departemen pada StringGrid yang tersedia

d. Inputkan Jumlah PC masing-masing departemen yang terdapat pada StringGrid.

Pada Halaman utama terdapat beberapa komponen untuk input jumlah departemen dan pilihan manual maupun otomatis. Semua dikelompokkan dalam sebuah GroupBox yang diberi nama IP System. Pada bagian input IP System terdapat 2 komponen yaitu:

1. ComboBox yang digunakan untuk menyimpan list jumlah departemen

2. RadioButton digunakan untuk menentukan pilihan sistem secara manual maupun otomatis. Untuk lebih jelasnya bisa dilihat pada gambar 4.

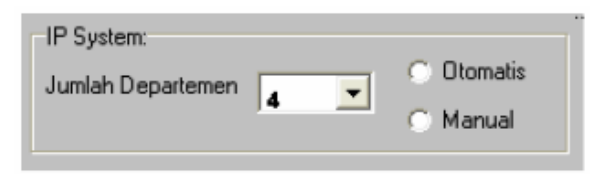

Gambar 4. Input IP System

Pada pilihan manual dibutuhkan inputan berupa IP Address yang akan di subnettkan. Untuk kebutuhan ini dibutuhkan sebuah komponen GroupBox yang diberi nama IP Address dan 4 buah komponen Edit. Dapat dilihat pada gambar 5.

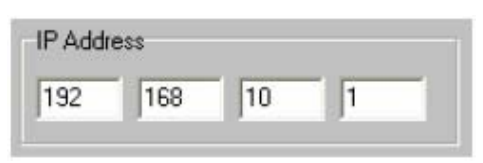

Gambar 5. Input IP Address

Selain itu untuk input nama departemen dan jumlah PC masing-masing departemen digunakan sebuah komponen StringGrid seperti pada gambar 6. 


\begin{tabular}{|l|l|l|}
\hline No & Nama Departemen & Jumlah PC \\
\hline $\mathbf{1}$ & Keuangan & 68 \\
\hline $\mathbf{2}$ & Pemasaran & 234 \\
\hline $\mathbf{3}$ & FrontOffice & 2 \\
\hline $\mathbf{4}$ & Service & 10 \\
\hline
\end{tabular}

Gambar 6. Input Nama Departemen dan Jumlah PC

Untuk menampilkan proses perhitungan sistem digunakan sebuah komponen memo seperti pada gambar 7 .

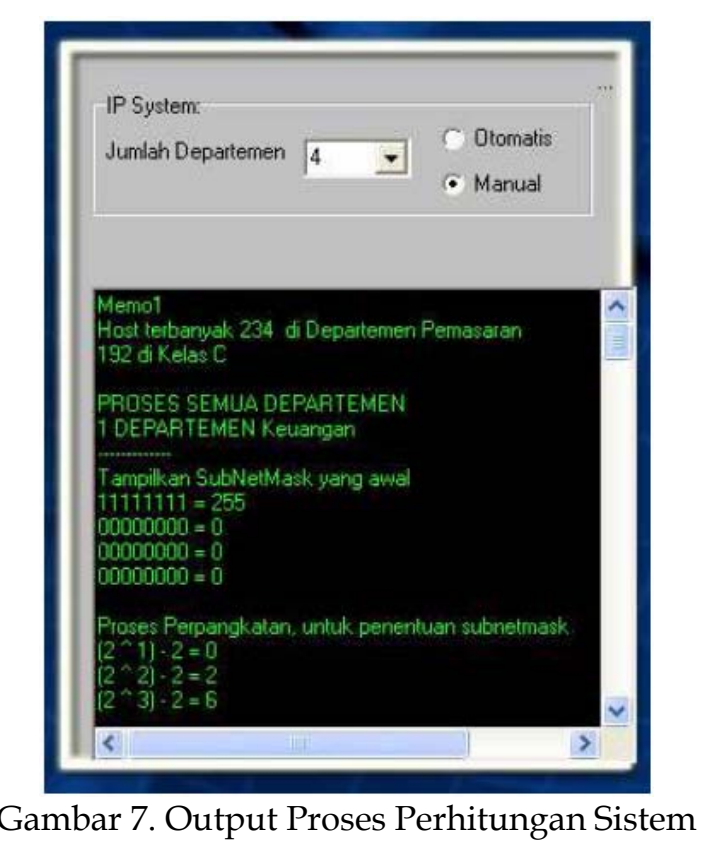

Untuk menjalankan pengolahan data yang telah diinputkan pada sistem kemudian menampilkan hasil proses di butuhkan sebuah komponen SpeedButton yang diberi nama tombol Proses seperti yang terlihat pada gambar 8 .

Sedangkan halaman tabel menampilkan hasil dari proses subnetting. Pada tampilan ini sistem akan menampilkan Output dari sistem berupa Nama Departemen, Network ID, Range IP, Alamat Broadcast dan Subnetmask. Halaman Tabel terlihat pada gambar 9 . 


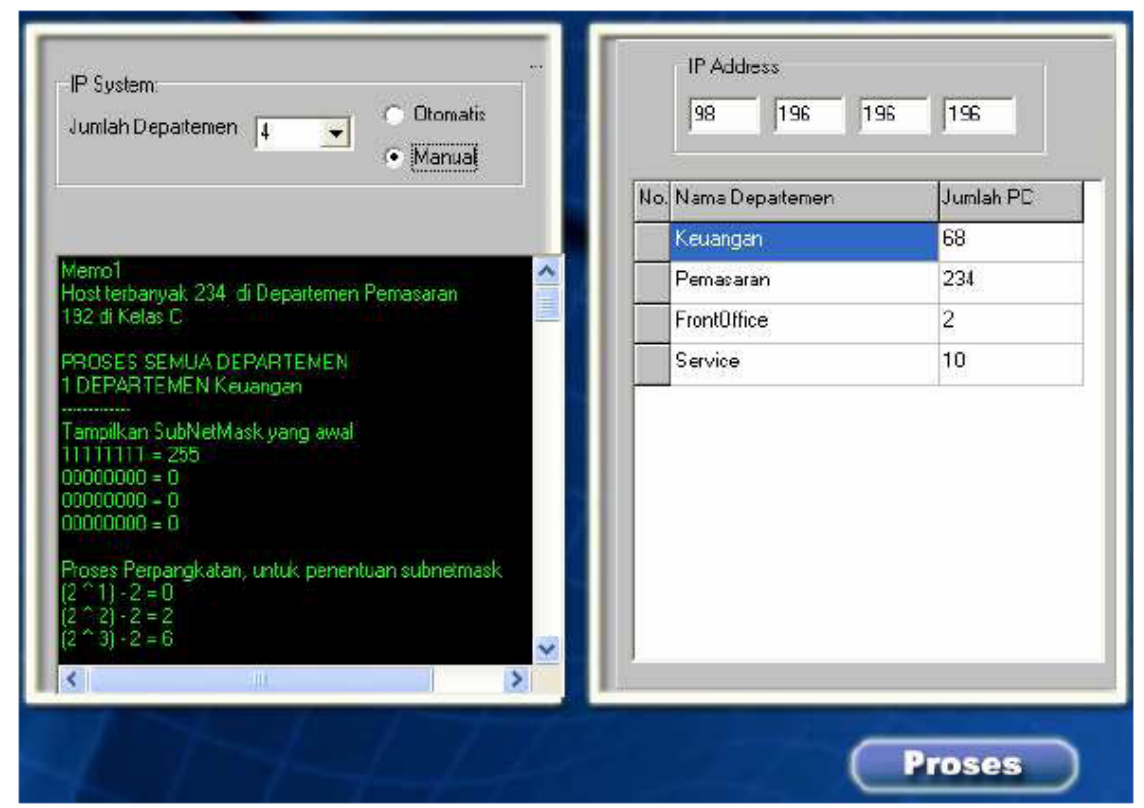

Gambar 8. Tombol Proses pada halaman Utama

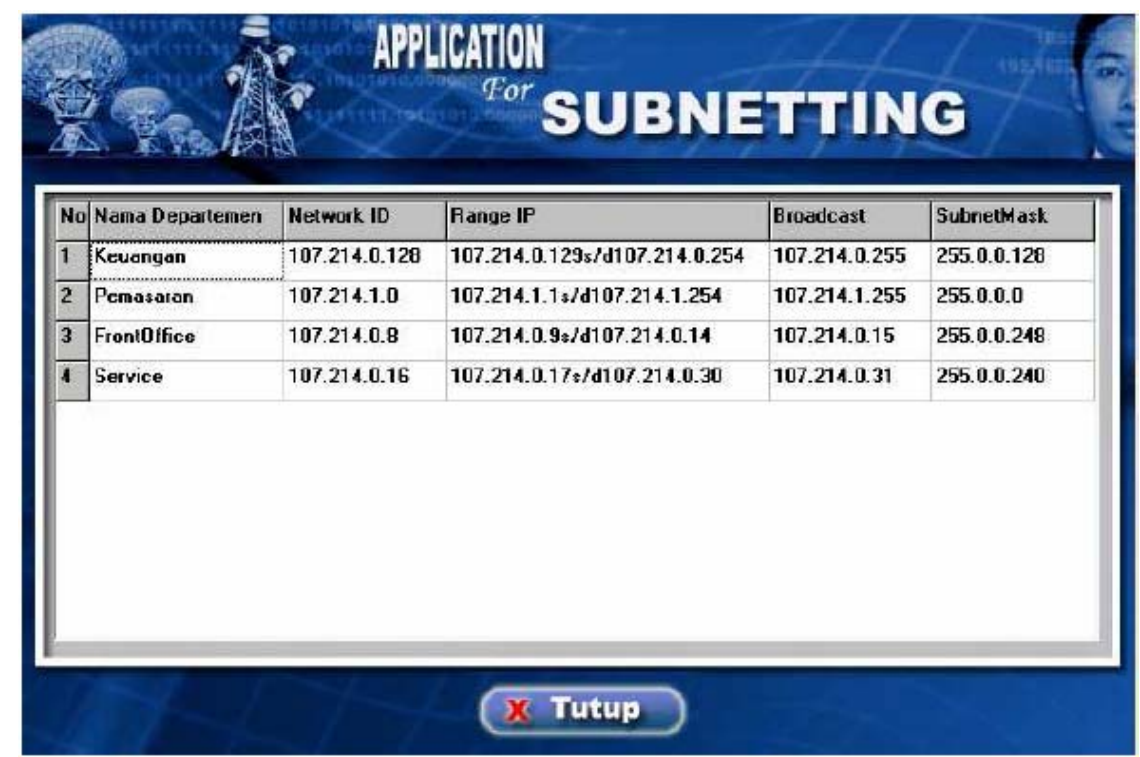

Gambar 9. Halaman Tabel

\section{SIMPULAN}

Setelah dilakukan analisis terhadap sistem aplikasi untuk menghitung IP address dan menentukan subnetmask, maka didapatkan beberapa kesimpulan sebagai berikut: 
1. Perangkat lunak yang dibuat menggunakan bahasa pemrograman Delphi 6.0 ini dapat digunakan untuk menyelesaikan permasalahan dalam penentuan IP address dan subnetmask dalam pengalamatan suatu jaringan berdasarkan jumlah PC yang telah diinputkan.

2. Pengujian sistem terhadap pemasukan data yang tidak benar memberikan hasil yang baik. Sistem mampu mengantisipasi kesalahan pemasukan data dengan memberikan pesan kesalahan pada user.

3. Untuk proses perhitungan otomatis, sistem bekerja dengan baik, user hanya memasukkan data jumlah PC tanpa memasukkan data IP address. Namun sistem dapat menentukan langsung IP address yang tepat beserta subnetmasknya berdasarkan jumlah PC yang telah dimasukan, sehingga memberikan kemudahan bagi user yang kurang memahami dalam penetuan kelas IP address.

\section{SARAN}

Berdasarkan pada pengujian yang telah dilakukan pada perangkat lunak yang dibuat, maka diperoleh beberapa saran untuk pengembangan perangkat lunak selanjutnya agar diperoleh kinerjanya yang lebih baik, yaitu sebagai berikut:

1. Fasilitas maupun komponen-komponen yang ada pada aplikasi untuk menghitung IP address dan menentukan subnetmask ini dapat ditambahkan dan dikembangkan lagi menjadi aplikasi yang lebih bagus.

2. Penentuan kelas IP yang digunakan tidak bergantung pada jumlah PC tertinggi pada suatu departemen saja sehingga departemendepartemen yang mempunyai jumlah PC yang lebih kecil juga dapat menentukan kelas IP nya masing-masing berdasarkan jumlah PC yang telah dimasukan.

\section{PUSTAKA}

Budi, (2003). Konsep dan Perancangan Jaringan Komputer, Yogyakarta, Penerbit Andi. Syafrizal. (2005). Penghantar Jaringan Komputer, Yogyakarta, Penerbit Andi.

Wagito. (2005). Jaringan Komputer Teori dan Implementasi Berbasis Linux, Jakarta, Penerbit Gavamedia.

Wahana Komputer. (2003). Konsep Jaringan Komputer dan Pengembangannya, Jakarta, Penerbit Salemba Infotek. 